\title{
Conservative-Force-Controlled Feed Drive System for Down Milling
}

\author{
Branko Tadic ${ }^{1}$ - Djordje Vukelic2,, - Janko Hodolic ${ }^{2}$ - Slobodan Mitrovic ${ }^{1}$ - Milan Eric ${ }^{1}$ \\ 1 Faculty of Mechanical Engineering, University of Kragujevac, Serbia \\ 2 Faculty of Technical Sciences, University of Novi Sad, Serbia
}

Reviewed in this paper are the results of theoretical and experimental investigation of a novel down milling method. The method is based on controlling feed speed using conservative forces, where the active force which provides motion is the horizontal component of the cutting force. Feed motion is therefore realized without any active forces (active drive systems), while the feed speed is regulated by precision breaking of the workpiece, which is possible through hydraulic damping. In addition to the basic theoretical model of the feed drive system, the paper also presents the dynamic model of the drive system, taking into consideration fluid compressibility. Based on the model proposed, a physical instance of the feed drive system was designed, built and tested. The results of preliminary experimental investigation speak in favour of the proposed theoretical model, which enables practical application of this type of feed drive systems.

(C) 2011 Journal of Mechanical Engineering. All rights reserved.

Keywords: down milling, special feed drive system, continuous feed speed control, damping

\section{INTRODUCTION}

Milling is a basic machining process by which a surface is generated progressively by the removal of chips from a workpiece as it is fed to a rotary cutter in a direction perpendicular to the axis of the cutter [1]. Surfaces can be generated by two methods: up milling (the cutter rotates against the direction of the feed of the workpiece) and down milling (the cutter rotates in the same direction of the feed of the workpiece). Both methods have some advantages and disadvantages [2].

In the past few years major attention has been given to research of the milling process. These research works refer to various aspects such as: influence of cutting parameters on surface roughness [3] to [5], dynamic problems in milling [6] to [8], tool wear in milling operations [9] and [10], stability of milling process [11] to [13], calculations of chip thickness in milling operations [14], optimal tool geometry selection [15], optimal tool path selection [16] to [18], optimization of machining parameters in milling using geometric programming [19], optimization of machining parameters in milling using genetic programming [20], optimization of machining parameters in milling operations using genetic algorithm [21] to [23], optimization of machining parameters in milling operations using artificial neural networks [24] and [25], optimization of machining parameters in milling operations using a combination of the genetic algorithm and artificial neural networks [26] and [27], optimization of machining parameters in milling operations using a combination of artificial neural networks and particle swarm [28].

This extensive research volume testifies of the importance of milling as machining technology. In spite of this, some core principles underlying kinematics and statics of cutting, have remained unchanged. The shape realized in any milling process depends on three important factors; tool geometry, workpiece geometry and relative motion between tool and the workpiece. The relative motion between tool and workpiece has two components. The first component of motion consists of the rotation of the tool around its own axis and the second is a feed motion of the workpiece relative to the tool. A combination of these two motions together with tool geometry and its interaction with the workpiece geometry defines the final shape of workpiece [1] and [2]. Having this in mind, a particularly significant machine tool component is the feed drive, which provides constant feed motion of the workpiece 
during machining. Considering the influence of feed motion on the surface quality and tool life, an important question is whether feed speed should be kept constant during the pass of a cutter tooth through workpiece material.

Analysis of dynamic movement equations leads to a conclusion that down milling can be performed in a completely different manner. The fact that during down milling the feed speed vector remains co-linear with the horizontal component of the cutting force, leads to an idea that conservative force can be used to control feed motion. Once the motion is initiated, the active cutting force maintains feed motion. Horizontal component of the cutting force can be used as an active force. Feed speed is controlled by an adequate conservative force. In that case, feed speed is not constant but depends on the magnitude of the horizontal component of the cutting force as well as on the characteristics of passive components, which serve to arrest the workpiece. Such a solution of the feed drive allows a braking system whose reaction-time is the magnitude of a hundredth of a second (under the influence of impulse forces), resulting in a very short braking path. With this type of feed speed control, the breaking path corresponds to the tooth pitch in conventional milling. Although it satisfies stringent demands, the technical solution of the conservative-force-controlled feed drive system is much simpler than that of conventional, mechanical systems, since braking is performed by simple hydraulic damping.

\section{MODEL OF FEED DRIVE SYSTEM}

With conventional milling machines, feed drives are designed as special transmission drives (gearbox, DC motor and recirculating-ball drive, etc.) which provide constant feed motion regardless of the magnitude of resisting forces which appear during cutting. At a constant feed speed, the workpiece is moving during cutting (i.e. during the passage of cutter tooth through workpiece material). In this case, during effective cutting time (tooth engagement) the relief surface of tooth cutting wedge is additionally loaded with an external force, which provides movement for the milling machine working table and workpiece. In comparison to conventional milling, the proposed milling method has completely different basics. It uses active cutting forces to produce feed motion, while feed speed is controlled using passive hydraulic components. Conceptual design of the proposed machining method is illustrated in Fig. 1.

If the workpiece is set in motion with the initial speed $v_{0}$, at a given moment in time, the cutter, rotating at a constant cutting speed, is going to engage with a segment of workpiece material.

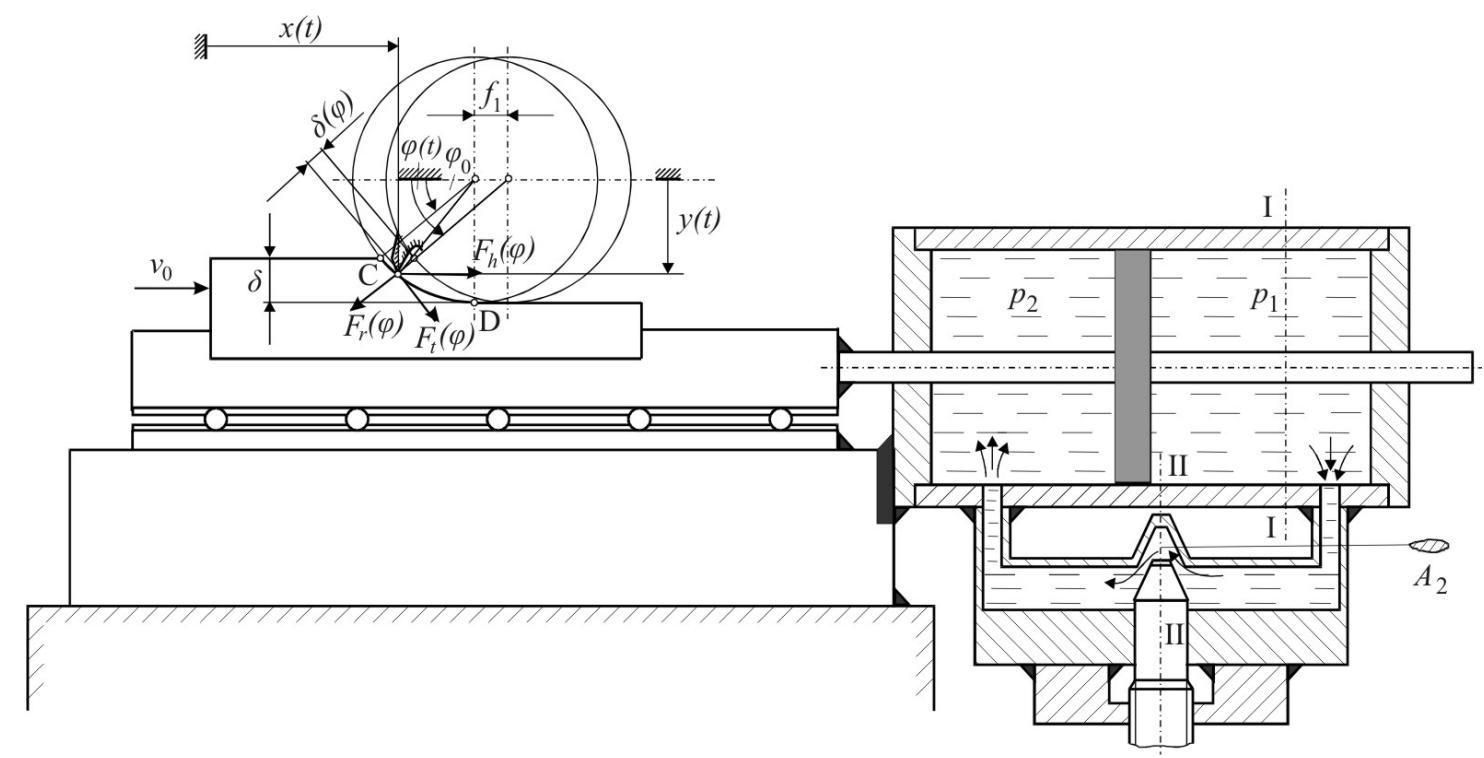

Fig. 1. Schema of the proposed feed drive system 
Horizontal component of the cutting force (Fig. 1), can be expressed by formula:

$$
F_{h}(\varphi)=F_{t}(\varphi) \sin \varphi-F_{r}(\varphi) \cos \varphi,
$$

where $F_{t}(\varphi)$ and $F_{r}(\varphi)$ are tangential and radial components of the cutting force, respectively.

The radial component of the cutting force can be expressed as:

$$
F_{r}(\varphi)=K \cdot F_{t}(\varphi),
$$

where $K$ is a constant which defines the ratio between radial and tangential components.

Substituting Eq. (2) into (1) gives:

$$
F_{h}(\varphi)=F_{t}(\varphi)(\sin \varphi-K \cdot \cos \varphi) .
$$

Analysis of Eq. (3) leads to a condition of movement which is derived from the following Eqs.:

$$
\begin{gathered}
F_{h}(\varphi)>0 \\
F_{t}(\varphi)>0 \\
K<\operatorname{tg} \varphi
\end{gathered}
$$

where $\varphi$ ranges between $\varphi_{0} \leq \varphi \leq 90^{\circ}$. Bearing in mind the cutting depths which are most frequently used in milling, it can be concluded that the condition of movement has been satisfied in most cases.

According to Fig. 1 current chip thickness is expressed as:

$$
\delta(\varphi)=f_{1} \cdot \cos \varphi,
$$

where $f$ is the movement of the workpiece (feed per tooth). Using known expressions for specific cutting resistance and tangential force, the horizontal component of the cutting force can be expressed as follows:

$$
\begin{gathered}
F_{h}(\varphi)=B_{o}(\sin \varphi-K \cos \varphi) \cos \varphi^{\left(1-1 / \varepsilon_{k}\right)}, \\
B_{o}=C_{k}\left(b \cdot f_{1}\right)^{1-\frac{1}{\varepsilon_{k}}},
\end{gathered}
$$

where $b$ is cutting width, while $B_{o}, C_{k}$ and $\varepsilon_{k}$ are constants depending on workpiece material.

Force $F_{h}(\varphi)$ creates the difference in pressures $\left(p_{1}-p_{2}\right)$ within the cylinder, so that Bernoulli equations applied to cross-sections $I-I$ and II-II give approximate equality of the following form:

$$
\frac{v_{k}^{2}}{2 g}+\frac{p_{1}}{\rho \cdot g}=\frac{v_{2}^{2}}{2 g}+\frac{p_{2}}{\rho \cdot g}+\sum_{I-I}^{I I-I I} h_{m},
$$

where $v_{k}$ denotes piston speed (i.e. workpiece speed), $p_{1}$ is pressure in the piston front-end, $v_{2}$ is speed of fluid in cross-section $I I-I I, p_{2}$ is pressure in the piston aft-end, $\Sigma h_{m}$ are total losses of mechanical energy on the streaming trajectory, from cross-section $I-I$ to cross-section $I I-I I, g$ is gravitational constant and $\rho$ is fluid thickness. All mechanical energy losses along fluid streaming path can be disregarded as lower order values in comparison with the losses in the throttling valve. From the continuity equations for the crosssections:

$$
\rho \cdot v_{k} \cdot A_{k}=\rho \cdot v_{2} \cdot A_{2},
$$

follows the speed of fluid through the throttling valve (cross-section $I I-I I)$ :

$$
v_{2}=\frac{A_{k}}{A_{2}} v_{k},
$$

where $A_{k}$ is the active surface area of piston, $A_{2}$ is the active surface area at the point of damping. Considering the surface areas ratio $\left(A_{k} / A_{2}\right)$ all the remaining losses in mechanical energy can be disregarded, compared to the losses in throttling valve, thus leading to:

$$
\sum_{I-I}^{I I-I I} h_{m}=\xi_{g} \frac{v_{2}^{2}}{2 g} \approx \sum h_{m},
$$

where $\xi_{g}$ denotes mechanical energy loss coefficient. Pressure drop is determined as the function of external load, using:

$$
\frac{\Delta p}{\rho \cdot g}=\frac{p_{1}-p_{2}}{\rho \cdot g}=\frac{F_{h}(\phi)}{\rho \cdot g \cdot A_{k}} .
$$

Substituting Eqs. (12), (13) and (14) into Bernoulli's Eq. (10) leads to:

$$
\begin{gathered}
\frac{v_{k}^{2}}{2 g}+\frac{F_{h}(\varphi)}{\rho \cdot g \cdot A_{k}}-\left(\frac{A_{k}}{A_{2}}\right)^{2} \frac{v_{k}^{2}}{2 g}- \\
-\xi_{g}\left(\frac{A_{k}}{A_{2}}\right)^{2} \frac{v_{k}^{2}}{2 g}=0 .
\end{gathered}
$$

Piston (workpiece) speed can be determined from Eq. (15), as the function of external load, fluid thickness and characteristic 
dimensions of the hydraulic assembly, using the following expression:

$$
v_{k}=\sqrt{\frac{2 F_{h}(\varphi)}{\rho \cdot A_{k}\left[\left(\frac{A_{k}}{A_{2}}\right)^{2}\left(1+\xi_{g}\right)-1\right]}} .
$$

There are two boundary states for feed motion.

1. The first boundary state pertains to a fully blocked system, when the throttling valve is closed $\left(A_{2} \rightarrow 0\right)$, turning Eq. (16) into:

$$
=\frac{v_{k 1}=\lim _{A_{2} \rightarrow 0} v_{k}=}{\sqrt{\frac{2 F_{h}(\varphi)}{\rho \cdot A_{k}\left[\left(\frac{A_{k}}{\varepsilon}\right)^{2}\left(1+\xi_{g}\right)-1\right]}}}=0,
$$

where $\varepsilon$ is an infinitely small value.

2. The second boundary state is a theoretical state in which $A_{2}=A_{k}$ and $A_{k} \rightarrow 0$, which means that:

$$
v_{k 2}=\lim _{\substack{A_{2} \rightarrow A_{k} \\ A_{k} \rightarrow 0}} v_{k}=\sqrt{\frac{2 F_{h}(\varphi)}{\rho \cdot \varepsilon \cdot \xi_{g}}} \rightarrow \infty .
$$

The first boundary state, with $v_{k}=0$, is practically achievable, and it can be proved that it is practically possible to create hydraulic design which provides continuous selection of feed speeds for all real cutting conditions. For down milling, it is the continuous selection of mean feed speed because feed speed is the function of horizontal cutting force component. form:

Eq. (16) can be expressed in following

$$
v_{k}=v_{p}=R_{k} \sqrt{F_{h}(\varphi)},
$$

where $R_{k}$, the constant of feed speed regulation, is expressed as:

$$
R_{k}=\sqrt{\frac{2}{\rho \cdot A_{k} \cdot\left[\left(\frac{A_{k}}{A_{2}}\right)^{2}\left(1+\xi_{g}\right)-1\right]}} .
$$

This is called the constant of feed speed regulation as it can be set to any value from zeroup to values which fit current cutting conditions.
Feed speed $v_{p}$ can be defined as the first derivative of traversed path, i.e. of coordinate $x$ in time:

$$
v_{p}=\frac{d x}{d t}=R_{k} \sqrt{F_{h}} .
$$

Using:

$$
\frac{d x}{d t}=\frac{d \varphi}{d t} \frac{d x}{d \varphi}=\Omega \frac{d x}{d \varphi},
$$

is derived:

$$
\Omega \frac{d x}{d \varphi}=R_{k} \sqrt{F_{h}(\varphi)},
$$

where $\Omega$ is the angular velocity of milling cutter. Based on the expression derived, it is possible to calculate total displacement of workpiece during single tooth cutting:

$$
f_{1}=\int_{x_{1}}^{x_{2}} d x=\frac{1}{\Omega} R_{k} \int_{\varphi_{o}}^{\pi / 2} \sqrt{F_{h}(\varphi)} d \varphi
$$

that is, by substituting $F_{h}(\varphi)$ from Eq. (8) into Eq. (24), there follows:

$$
\begin{aligned}
& f_{1}=\frac{R_{k}}{\Omega} . \\
& \cdot \int_{\varphi_{o}}^{\pi / 2} \sqrt{B_{o}(\sin \varphi-K \cos \varphi) \cos \varphi^{\left(1-\frac{1}{\varepsilon_{k}}\right)} d \varphi} .
\end{aligned}
$$

Should the value of this integral be denoted with $I_{1}$, there follows:

$$
f_{1}=\frac{R_{k}}{\Omega} I_{l} .
$$

The value of integral $I_{1}$ corresponds to the area shown in Fig. 2. The size of the area in Fig. 2, i.e. the value of integral $I_{1}$ can be calculated as:

$$
I_{1}=\sqrt{F_{h}\left(\varphi_{M}\right)}\left(\frac{\pi}{2}-\varphi_{o}\right)=\sqrt{F_{h}\left(\varphi_{M}\right)} \varphi_{z},
$$

where $\varphi_{z}$ is the angle of tooth engagement, and $\sqrt{F_{h}\left(\varphi_{M}\right)}$ denotes mean value of function $\sqrt{F_{h}(\varphi)}$ which defines cutting conditions and has a constant value.

By substituting Eqs. (27) to (26) the final expression, which defines displacement of workpiece during engagement of a single tooth is derived:

$$
f_{1}=\frac{R_{k} \sqrt{F_{h}\left(\varphi_{M}\right)} \varphi_{z}}{\Omega} .
$$

An analysis of this expression leads to the conclusion that workpiece displacement (the value of feed motion) also depends on the speed 
of primary motion. With this method of milling, the feed speed, $v_{p}$, and feed per tooth, $f_{1}$, are not constant but vary as the function of the horizontal component of the cutting force. Fig. 3 shows theoretical dependence of $F_{h}(t), v_{p}(t)$, and $L(t)$ on the time of machining.

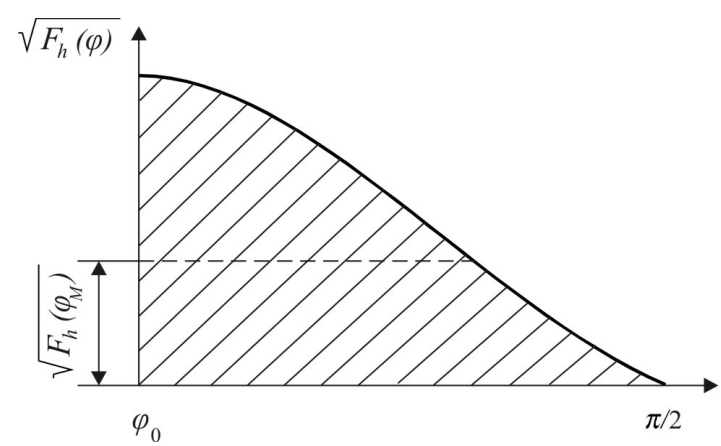

Fig. 2. Graph of integral $I_{1}$

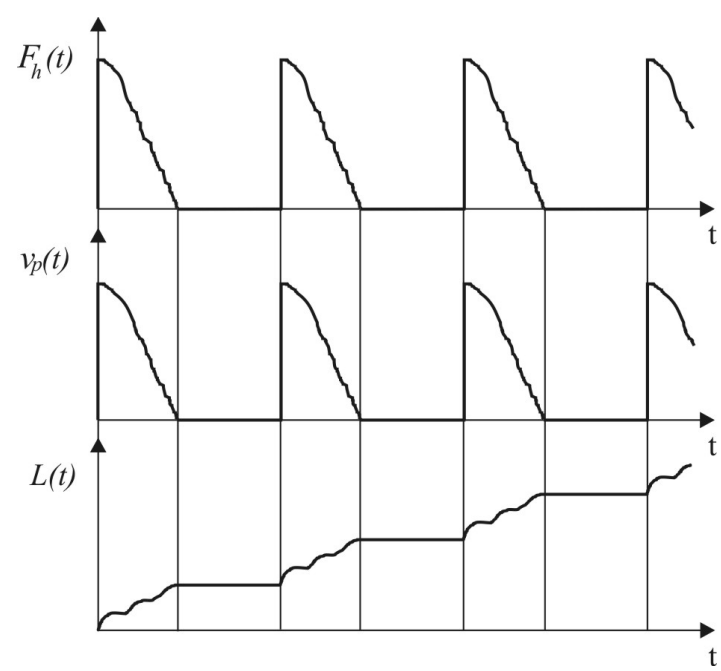

Fig. 3. Dependence of horizontal component of cutting force $F_{h}(t)$, feed speed $v_{p}(t)$, and traversed path $L(t)$ on time $t$

Control of feed motion using horizontal component of the cutting force differs from conventional methods for feed motion control in milling, in the following:

- displacement of workpiece takes place only during engagement with tooth (teeth), while in the case of conventional milling the displacement takes place at a constant rate,

- by regulating flow by throttling valve continuous control of the mean feed speed can be achieved, while the conventional gearboxes on milling machines allow this change only stepwise, and

- feed speed is variable and ranges from the selected value at point $\mathrm{C}$, down to zero at point $\mathrm{D}$ (Fig. 1), which belongs to the machined surface.

However, it should be noted that both the conventional milling and the milling method which uses conservative forces to control feed speed, represent special cases of a more general theoretical milling method.

If, besides cutting forces, the workpiece is under the influence of an active force, $F_{a k}$, which acts in the direction of feed motion, then feed speed can be calculated as:

$$
v_{p}=R_{k} \sqrt{F_{a k}+F_{h}(t)} .
$$

For larger values of $F_{a k}$, i.e. in cases when $F_{a k} \gg F_{h}(t)$, feed speed is approximately constant, rendering this method equivalent to conventional down milling. When active forces are smaller $\left(F_{a k}<<F_{h}(t)\right)$ this milling method employs feed speed control as described above.

Previous theoretical analysis ignored the compressibility of fluid which fills the hydraulic cylinder. However, for the purpose of practical realization of conservative-force-controlled feed drive, a detailed analysis of dynamic equations was conducted, taking into account fluid (oil) compressibility.

\section{DYNAMIC MODEL OF THE FEED DRIVE SYSTEM}

As mentioned above, previous analysis revealed basic relationships between feed speed, displacement, and active force (horizontal component of the cutting force), but failed to give the real picture of dynamic behaviour of the feed speed drive. One of the basic problems related to modelling of dynamic behaviour of feed drives is the real compressibility of the fluid which fills up the cylinder of hydraulic assembly. Fig. 4, which shows dynamic model of the feed drive, can be used to analyze forces and displacement. The system is loaded in the direction of feed motion with following forces: horizontal component of cutting force $\left(F_{h}\right)$, the resulting inertial force $(F i n)$, friction force $\left(F_{T}\right)$, resistance of throttling valve 
$\left(F_{p}\right)$, and elastic force which is the result of fluid compressibility $\left(F_{e}\right)$.

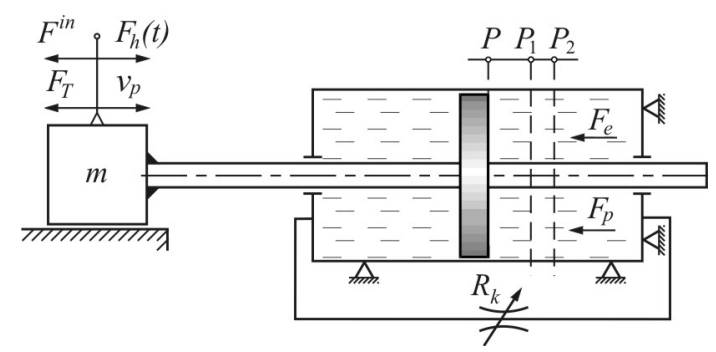

Fig. 4. Diagram of dynamic model of feed drive system

Under the influence of the stated forces, during the finite time interval $\Delta t$, the piston shall traverse path from point $P$ to point $P_{2}$. The path $\overline{P P_{1}}$ traversed by the piston is proportional to the volume of fluid passing through the throttling valve during $\Delta t$ interval, while the piston displacement $\overline{P_{1} P_{2}}$ is the result of fluid compressibility. A dynamic model of the feed drive system (Fig. 4) has two degrees of freedom. Total displacement of workpiece comprises the controlled segment $\overline{P P_{1}}$, which is regulated by the damping rate, and the segment $\frac{P_{1} P_{2}}{P^{2}}$ which is not subject to control. The displacement $\overline{P_{1} P_{2}}$ depends on the coefficient of compressibility and the geometry of hydraulic cylinder. For the expected load level during machining, the flow speed of real fluid does not differ significantly from the flow speed of ideal fluid. Bearing this in mind, the dynamic model of feed drive can be represented by Fig. 5 .

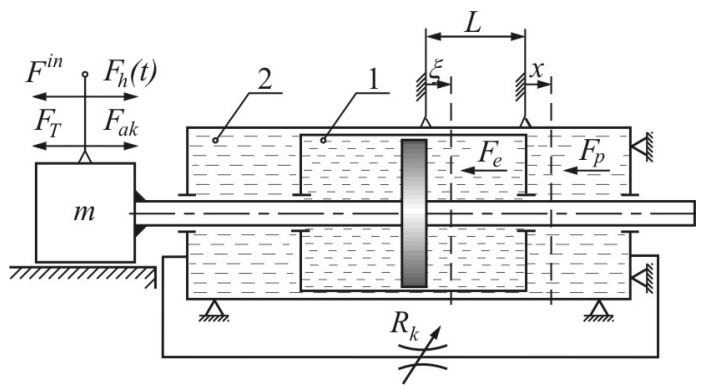

Fig. 5. Dynamic model of feed drive system

In cylinder 1 there is a real compressible fluid, while cylinder 2 contains the ideal, incompressible fluid. The resulting force shall influence displacement along $\xi$ and $x$ coordinates. Force balance equation for this system is:

$$
\vec{F}^{i n}+\vec{F}_{e}+\vec{F}_{p}+\vec{F}_{T}+\vec{F}_{h}+\vec{F}_{a k}=0 .
$$

Inertial force Fin represents the total system inertial force and can be expressed as:

$$
F^{i n}=m \frac{d^{2} \xi}{d t^{2}}+m \frac{d^{2} x}{d t^{2}}
$$

where $m$ is the total movable mass (slider, piston rod, etc.), $\xi$ denotes piston displacement due to compression of the real-compressible fluid, while $x$ is piston displacement allowed by the selected damping coefficient.

From the equation:

$$
s=\frac{1}{V} \frac{d V}{d p}=\frac{A_{k} \cdot d \xi}{A_{k} \cdot L \frac{1}{A_{k}} d F_{e}},
$$

follows that the elastic force $F_{e}$ equals:

$$
F_{e}=\frac{A_{k}}{s \cdot L} \xi,
$$

where the stiffness is defined by the ratio $\left(A_{k} /\right.$ $\left.s^{\times} \times L\right)$, and $A_{k}$ is the active piston surface area, $s$ is oil compressibility coefficient, and $L$ is the length of cylinder at the front of the piston at the observed moment in time. Damping force $F_{p}$ can be determined based on Eq. (19). The magnitude of this force retains its form of dependence, and can be calculated as function of piston speed:

$$
\begin{gathered}
F_{p}=\frac{1}{R_{k}} \cdot\left(\frac{d x}{d t}\right)^{2} \cdot \operatorname{sgn}\left(\frac{d x}{d t}\right), \\
F_{p}=R_{r} \cdot\left(\frac{d x}{d t}\right)^{2} \cdot \operatorname{sgn}\left(\frac{d x}{d t}\right),
\end{gathered}
$$

where $R_{r}$ is reciprocal value of the regulation constant $R_{k}$ given in Eq. (20), and $d x / d t$ is the speed of piston due to flow of fluid through the throttling valve.

Damping force $F_{p}$ is the conservative force used to control the down milling feed. In conventional milling this force does not exist, while feed is controlled in a completely different way.

Friction force $F_{T}$ represents the sum of all friction forces on movable feed drive components. Bearing in mind the feed drive design (the built-in 
linear roller guides) for the most part, the friction force can be neglected. The magnitude of active force $F_{a k}$ can be chosen arbitrarily, while the horizontal component of the cutting force, as a smooth function of time, can be defined as:

$$
\begin{aligned}
& F_{h}(t)=\frac{F_{t \max } \Phi[-\sin (\Omega t+\beta)] \Phi(\sin \Omega t)}{\sin \beta} . \\
& \cdot \sin \Omega t(\cos \Omega t+K \sin \Omega t)
\end{aligned}
$$

where $\Phi$ is Heaviside function, and $F_{\text {tmax }}$ is the maximum value of the tangential component of the cutting force.

Based on the forces defined, the differential equation of displacement can be set:

$$
\begin{aligned}
& m \frac{d^{2} \xi}{d t^{2}}+m \frac{d^{2} x}{d t^{2}}+\frac{A_{k}}{s L} \xi+ \\
& +R_{r}\left(\frac{d x}{d t}\right)^{2} \cdot \operatorname{sgn}\left(\frac{d x}{d t}\right)=F_{h}(t)+F_{a k} .
\end{aligned}
$$

There is a following relationship between the elastic force $F_{e}$ and damping force $F_{p}$ :

$$
\frac{A_{k}}{s L} \xi=R_{r}\left(\frac{d x}{d t}\right)^{2} \cdot \operatorname{sgn}\left(\frac{d x}{d t}\right),
$$

from which the following is derived:

$$
\frac{A_{k}}{s \cdot L} \frac{d \xi}{d t}=2 R_{r}\left(\frac{d x}{d t}\right) \frac{d^{2} x}{d t^{2}},
$$

while the acceleration follows from:

$$
\frac{d^{2} x}{d t^{2}}=\frac{1}{2} \sqrt{\frac{A_{k}}{s \cdot L \cdot R_{r} \cdot \xi}} \frac{d \xi}{d t} .
$$

For both senses of motion the same damping rate was adopted, i.e.:

$$
R_{r}(x<0)=R_{r}(x>0),
$$

although a solution can be found for other damping rates. By substituting both Eq. (40) and relationships between elastic and damping forces into Eq. (37), a nonlinear differential equation is derived:

$$
\begin{aligned}
& m \frac{d^{2} \xi}{d t^{2}}+\frac{m}{2} \sqrt{\frac{A_{k}}{s \cdot L \cdot R_{r} \cdot \xi}} \frac{d \xi}{d t}+ \\
& \frac{2 A_{k}}{s \cdot L} \cdot \xi=F_{h}(t)+F_{a k}
\end{aligned}
$$

The problem is now reduced to defining the law of motion $\xi(t)$. Analysis of differential Eq. (37) leads to the conclusion that the magnitude of displacement $\xi$ depends, among other factors, on the damping rate $R_{r}$. Observing the boundary condition of the system when the throttling valve is completely blocked (closed), it can be concluded that the displacement $x$ equals zero, reducing Eq. (37) to the following form:

$$
m \frac{d^{2} \xi}{d t^{2}}+\frac{A_{k}}{s \cdot L} \xi=F_{h}(t)+F_{a k} .
$$

In this boundary case, the total work of external forces $F_{a k}$ and $F_{h}(t)$ shall be spent on fluid compression in cylinder 1 . The magnitude of this work depends on the magnitude of damping rate $R_{r}$, so $\xi$ - which is derived from Eq. (43) - has the largest possible value. Thus, the law by which $\xi(t)$ changes in time can be expressed by:

$$
m \frac{d^{2} \xi}{d t^{2}}+\frac{A_{k}}{s \cdot L} \xi=Z\left[F_{h}(t)+F_{a k}\right],
$$

where $Z$ is an unknown constant. Eq. (44) has an analytical solution, which is given here in its final form:

$$
\begin{aligned}
& \xi(t)=A_{1}(t) \cos \omega t+B_{1}(t) \sin \omega t+ \\
& +C_{1}(t) \sin 2 \Omega t+D_{1}(t) \sin ^{2} \Omega t+E_{1}(t),
\end{aligned}
$$

where $\Omega$ is forced frequency, $\omega$ is eigenfrequency. Eigenfrequency is given as:

$$
\omega=\sqrt{\frac{A_{k}}{s \cdot L \cdot m}},
$$

while the remaining parameters follow from:

$$
\begin{gathered}
h_{1}(t)=\frac{-F_{t \max } \cdot Z}{m \cdot \sin \beta} \Phi(\sin \Omega t) \\
\Phi[-\sin (\Omega t+\beta)] \\
h_{2}=\frac{F_{a k}}{m}, \\
C_{1}(t)=\frac{0,5 h_{1}(t)}{\omega^{2}-4 \Omega^{2}}, \\
D_{1}(t)=\frac{h_{1}(t) K}{\omega^{2}-4 \Omega^{2}}, \\
E_{1}(t)=\frac{h_{2}-2 \Omega^{2} D_{1}(t)}{\omega^{2}},
\end{gathered}
$$




$$
\begin{gathered}
B_{1}(t)=\frac{-2 \Omega C_{1}(t)}{\omega}, \\
A_{1}(t)=\frac{s \cdot L}{A_{k}} F_{a k}-E_{1}(t) .
\end{gathered}
$$

The law of change $\xi(t)$, defined by Eq. (45) and a constant $Z=0.5$, identically satisfy Eq. (41) for any $m, A_{k}, s, L, R_{r}$ and forces $F_{h}(t)$, and $F_{a k}$.

The speed of fluid compression $\left(v_{2}\right)$ in the hydraulic cylinder is calculated as a derivative of displacement $\xi(t)$ in time:

$$
\begin{aligned}
& v_{2}(t)=\frac{d \xi}{d t}= \\
& =-A_{1}(t) \omega \sin \omega t+B_{1}(t) \omega \cos \omega t+ \\
& +2 \Omega C_{1}(t) \cos 2 \Omega t+D_{1}(t) \Omega \sin 2 \Omega t,
\end{aligned}
$$

while the controlled segment of speed $\left(v_{1}\right)$ can be calculated as:

$$
v_{1}=\frac{d x}{d t}=\sqrt{\frac{A_{k}}{s \cdot L \cdot R_{r}} \xi} .
$$

Workpiece feed speed equals the sum of $v_{1}$ and $v_{2}$, that is:

$$
v_{p}=v_{1}+v_{2},
$$

while the total displacement of workpiece equals:

$$
x_{p}(t)=\xi(t)+x(t)=\xi(t)+\int_{0}^{t} v_{1}(t) d t .
$$

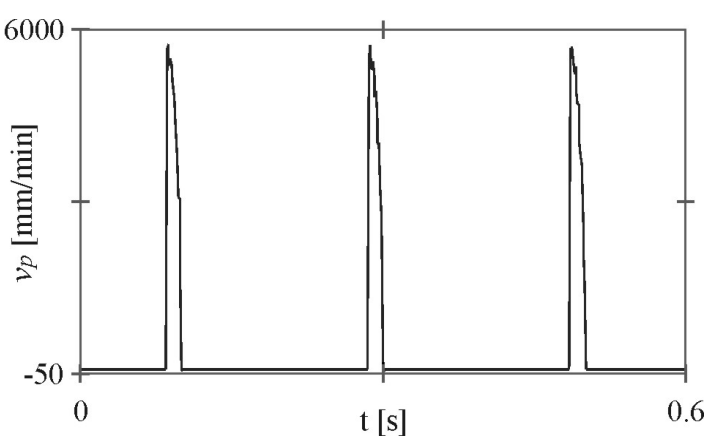

Fig. 6. Feed speed resulting from dynamic model with following inputs $F_{\text {tmax }}=3000 \mathrm{~N}$;

$F_{r} / F_{t}=0.7 ; \mathrm{s}=3 \times 10^{-10} \mathrm{~m}^{2} / \mathrm{N} ; \mathrm{W}=31.4 \mathrm{~s}^{-1} ;$ $m=50 \mathrm{~kg} ; L=0.2 \mathrm{~m} ; A_{k}=0.0144 \mathrm{~m}^{2}, F_{a k}=0 \mathrm{~N}$; $R_{r}=10^{5} \mathrm{~N}^{1 / 2} \mathrm{~s} / \mathrm{m}, \delta=5 \mathrm{~mm} ; D=100 \mathrm{~mm}$

Based on the equations given above, a software application was made which allows calculation of current feed speeds and workpiece displacements, for various input values.

Shown in Figs. 6 and 7 are diagrams of boundary feed speeds which are the result of two different damping rates $R_{r}=105 \mathrm{~N}^{1 / 2} \mathrm{~S} / \mathrm{m}$ (Fig. 6), and $R_{r}=1010 \mathrm{~N}_{1 / 2} \mathrm{~s} / \mathrm{m}$ (Fig. 7).

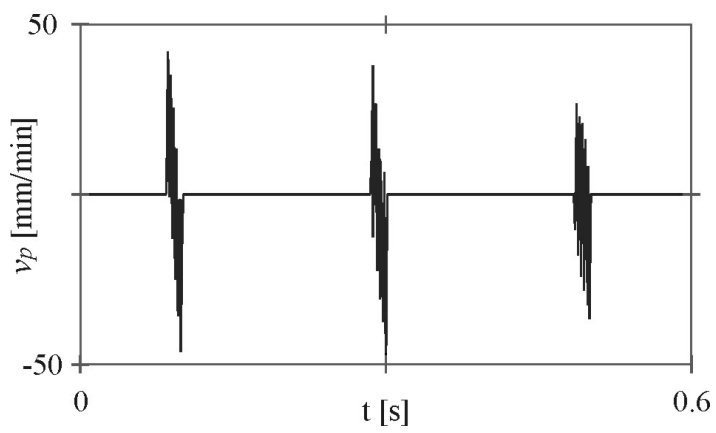

Fig. 7. Feed speed resulting from dynamic model with following inputs $F_{t \max }=3000 \mathrm{~N} ; F_{r} / F_{t}=$ $0.7 ; s=3 \times 10^{-10} \mathrm{~m}^{2} / \mathrm{N} ; W=31.4 \mathrm{~s}^{-1} ; \mathrm{m}=50 \mathrm{~kg}$; $L=0.2 \mathrm{~m} ; A_{k}=0.0144 \mathrm{~m}^{2}, F_{a k}=0 \mathrm{~N} ; R_{r}=10^{10}$ $N^{1 / 2} \mathrm{sm}^{-1}, \delta=5 \mathrm{~mm} ; D=100 \mathrm{~mm}$

It should be noted that higher damping rates $R_{r}$ (Fig. 7) prohibit machining by the proposed technology. Namely, there is an area of damping rates $R_{r}$ and stiffness $\left(A_{k} / s^{\times} L\right)$ which provides sufficient displacement of workpiece. For particular stiffness, the level of damping rate $R_{r}$ can be selected such as to allow cutting with feed speeds common to milling, which is shown in Figs. 8 to 10.

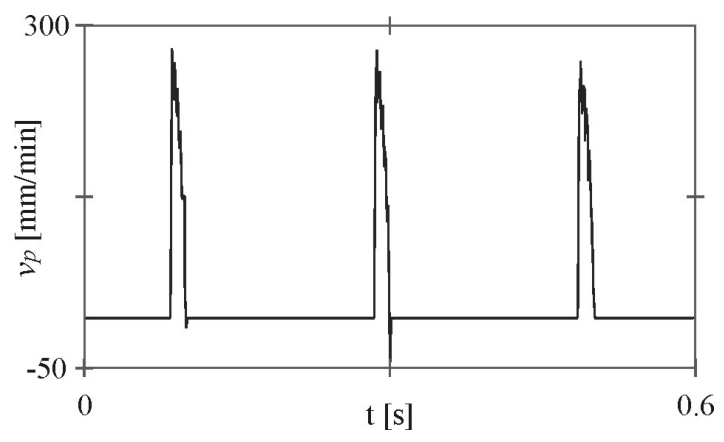

Fig. 8. Feed speed resulting from dynamic model with following inputs $F_{\text {tmax }}=3000 \mathrm{~N} ; F_{r} / F_{t}=0.7$;

$s=3 \times 10^{-10} \mathrm{~m}^{2} / \mathrm{N} ; W=31.4 \mathrm{~s}^{-1} ; \mathrm{m}=50 \mathrm{~kg} ;$

$L=0.2 \mathrm{~m} ; A_{k}=0.0144 \mathrm{~m}^{2}, F_{a k}=0 \mathrm{~N}$;

$R_{r}=5 \times 10^{7} \mathrm{~N}^{1 / 2} \mathrm{sm}^{-1}, \delta=5 \mathrm{~mm} ; D=100 \mathrm{~mm}$ 


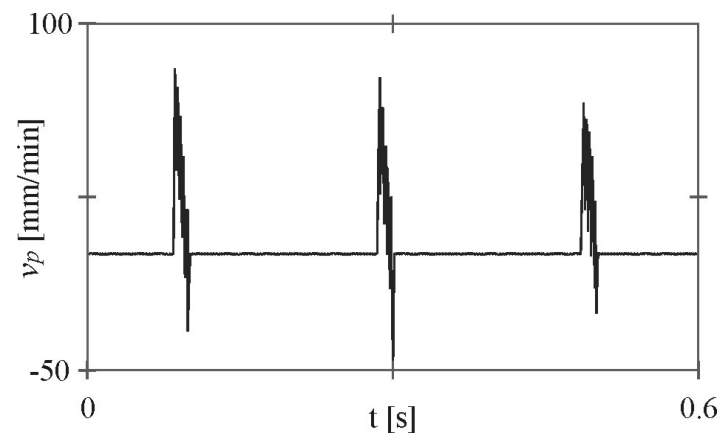

Fig. 9. Feed speed resulting from dynamic model with following inputs $F_{\text {tmax }}=3000 \mathrm{~N} ; F_{r} / F_{t}=0.7$; $s=3 \times 10^{-10} \mathrm{~m}^{2} / \mathrm{N} ; W=31.4 \mathrm{~s}^{-1} ; \mathrm{m}=50 \mathrm{~kg} ;$

$L=0.2 \mathrm{~m} ; A_{k}=0.0144 \mathrm{~m}^{2}, F_{a k}=0 \mathrm{~N}$;

$R_{r}=5 \times 10^{8} \mathrm{~N}^{1 / 2} \mathrm{sm}^{-1}, \delta=5 \mathrm{~mm} ; D=100 \mathrm{~mm}$

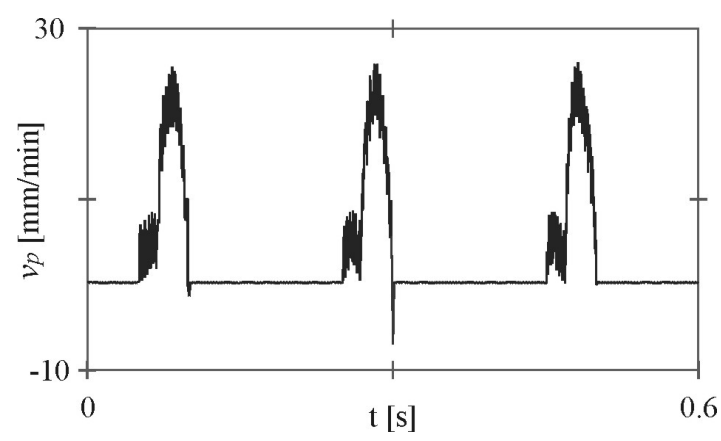

Fig. 10. Feed speed resulting from dynamic model with following inputs $F_{\text {tmax }}=1000 \mathrm{~N} ; F_{r} / F_{t}=0.7$;

$$
\begin{gathered}
s=3 \times 10^{-10} \mathrm{~m}^{2} / \mathrm{N} ; W=31.4 \mathrm{~s}^{-1} ; \mathrm{m}=50 \mathrm{~kg} ; \\
L=0.2 \mathrm{~m} ; A_{k}=0.0144 \mathrm{~m}^{2}, F_{a k}=2000 \mathrm{~N} ; \\
R_{r}=10^{9} \mathrm{~N}^{1 / 2} \mathrm{sm}^{-1}, \delta=5 \mathrm{~mm} ; D=100 \mathrm{~mm}
\end{gathered}
$$

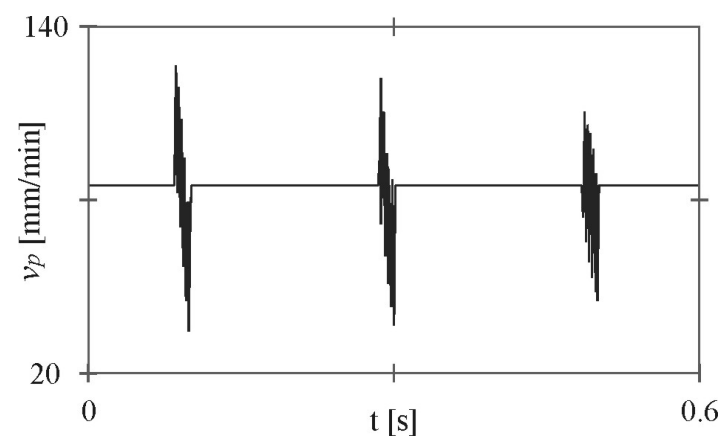

Fig. 11. Feed speed resulting from dynamic model with following inputs $F_{\text {tmax }}=3000 \mathrm{~N} ; F_{r} / F_{t}=0.7$;

$$
\begin{gathered}
s=3 \times 10^{-10} \mathrm{~m}^{2} / \mathrm{N} ; W=31.4 \mathrm{~s}^{-1} ; \mathrm{m}=50 \mathrm{~kg} ; \\
L=0.2 \mathrm{~m} ; A_{k}=0.0144 \mathrm{~m}^{2}, F_{a k}=2000 \mathrm{~N} ; \\
R_{r}=10^{9} \mathrm{~N}^{1 / 2} \mathrm{sm}^{-1}, \delta=5 \mathrm{~mm} ; D=100 \mathrm{~mm}
\end{gathered}
$$

If, in addition to the horizontal component of the cutting force, active force $F_{a}$ is also acting upon piston rod, then the proposed feed drive dynamically behaves similarly to the conventional one. Fig. 11 shows the law of feed speed change in case of an active force of higher magnitude.

Total displacement of the workpiece, defined by Eq. (57), also comprises displacement component $\xi$ which is not subject to control. The magnitude and law of change of displacement $\xi(t)$ depend on the following parameters: the stiffness of hydraulic assembly $\left(A_{k} / s \times L\right)$, magnitude and ratio between the radial and tangential cutting force $\left(F_{r}, F_{t}, K\right)$, mass of movable feed drive components $(m)$, cutter diameter $(\delta)$, cutting depth $(D)$, and angular speed of the cutter $(\Omega)$. For particular values of these parameters and within some period of cutting, the displacement $\xi$ reaches its maximum. It is of utmost importance to choose such construction parameters $A_{k}, s, L$, and $m$, which would for the expected magnitudes of cutting force components allow the uncontrollable $\xi$ to be kept at insignificant level. This can be realized by increasing the stiffness of the hydraulic assembly. Values of stiffness $\left(A_{k} / s \times L\right)$ and mass $(m)$ should be chosen in such a mannerthat given real machining conditions system oscillations are kept out of the resonance area.

The magnitude of resonant frequency is defined by:

$$
\Omega=\frac{1}{2} \sqrt{\frac{A_{k}}{s \cdot L \cdot m}} .
$$

An analysis of the Eq. (58) shows that the resonance area is above the real frequency of impulse forces inherent to milling. This frequency rarely oversteps $400 \mathrm{~Hz}$. Thus, the magnitude of hydraulic assembly stiffness and the mass of movable drive components, can be easily chosen so that the magnitude of eigenfrequency is $10^{4}$ $\mathrm{Hz}$ and higher. Figs. 12 and 13 show a change of displacement $\xi$ in time, for various angular speeds of the cutter. Simulation of displacement $\xi$, was performed with following parameter values: $\max$. circumferential force $F_{\text {tmax }}=3000 \mathrm{~N}$, ratio between radial and tangential cutting force $K=0.6$, cutter diameter $\delta=100 \mathrm{~mm}$, cutting depth $D=20 \mathrm{~mm}$, coefficient of fluid (oil) compressibility $s=3 \times 10^{-10} \mathrm{~m}^{2} / \mathrm{N}$, mass of movable components $m=50 \mathrm{~kg}$, observed cylinder length 
$L=0.2 \mathrm{~m}$, and active piston area $A_{k}=0.014 \mathrm{~m}^{2}$. For the given machining conditions, the maximum value of uncontrollable displacement $\xi(t)$ does not overstep $3 \mathrm{~mm}$ (Figs. 12 and 13), which makes it practically possible to establish control from zero to the desired value by shifting $x$.

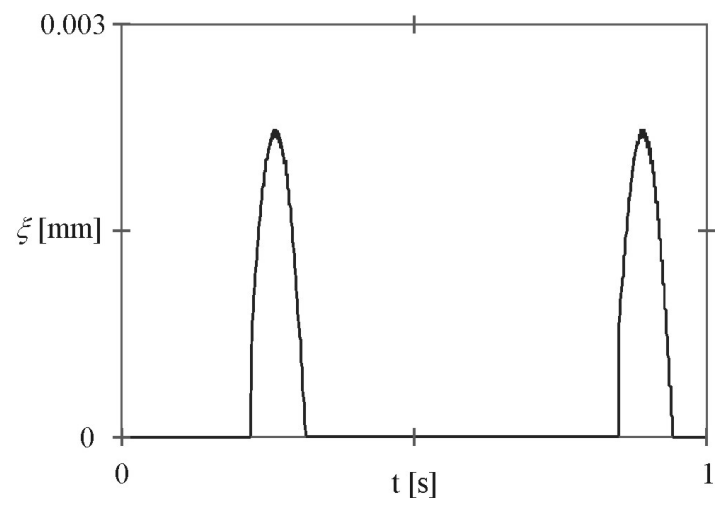

Fig. 12. Dependence of displacement $\xi$ on cutting time interval, at angular speed $\Omega=10 \mathrm{~s}^{-1}$

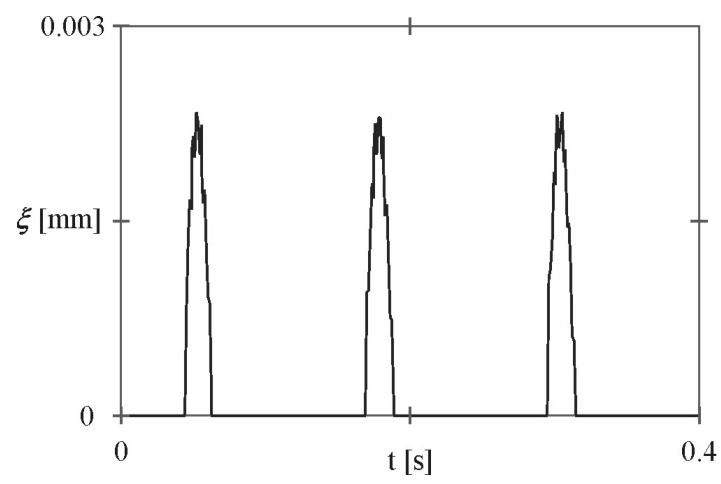

Fig. 13. Dependence of displacement $x$ on cutting time interval, at angular speed $\Omega=50 \mathrm{~s}^{-1}$

\section{DESIGN OF FEED DRIVE SYSTEM}

The results of the theoretical analysis from previous sections were used to design a physical prototype of the feed drive system for down milling operations. This feed drive system establishes control over the feed motion based on the horizontal component of the cutting force. Feed drive components are designed in such a way that they allow continuous shift of feed speed within the $v_{p}=0$ to $500 \mathrm{~mm} / \mathrm{min}$ interval, at the maximum value of the horizontal component of the cutting force $F_{\text {hmax }}<10000 \mathrm{~N}$.
For the sake of brevity, only a segment of design solution with some specific details is presented here. Based on the diagram in Fig. 14 characteristic components of the feed drive system are labeled and the functioning of particular subassemblies is given. The workpiece (1) is located and clamped in the fixture (2), which is screwed onto the movable slider (3) of the feed drive worktable. The worktable (3) consists of a movable slider, standard linear and roller guides, and table body with preloading screws. The linear roller guides are protected against chip by special metal sheet elements (4), while the entire assembly is tied to the base plate (5), which is screwed down to the worktable. The movable slide of the worktable is connected to the piston rod (6) through a special carrier. This connection works through a lever (7), piston rod extension (8), axle (9) and screws. Lever (7), piston rod extension (8) and axle (9) are connected without any clearance, which, during assembly, allows total alignment of kinematic axes of piston rod and worktable slider. In addition, this connection does not allow torque transfer, which means that the piston rod is loaded with axial force only. Piston rod (6) is common to brake cylinder (10) and pneumatic cylinder (11), which are screwed down to base plate via holders (12) to (14). Left and right chamber of hydraulic cylinder are connected via a throttling valve (10a), which regulates feed speed. The same line also includes a unidirectional blocking valve (10b) in order to increase velocity of backstroke. Motion is initiated via a pneumatic cylinder (11) which is fed by compressed air - distributed via air service unit (11a) and a sliding valve (11b) into the cylinder's left chamber. At backstroke, the air is fed into the right chamber of the pneumatic cylinder, so the fluid (oil) from the left chamber of the hydraulic cylinder flows through the throttle valve and through unidirectional blocking valve, which allows a much faster execution of backstroke. Attached to the holder (12) of the hydraulic cylinder is support (15). The support has a groove which allows inductive sensors - (16) (start) and (17) (stop) - to be mounted at distance $L$ and activated by platelet (18) which is mounted on support (7). These sensors are connected to a timer (19). Based on the known path $L$ and elapsed time $t$, which is read on timer display, it is possible to calculate the mean feed speed - for the 
chosen damping rate and machining parameter. Hydraulic cylinder is equipped with a throttling valve (10c) which controls oil feed to the cylinder. During feeding, the throttling valve (10a) is open due to alternate movements of piston rod and air let-off. In order to eliminate negative effects of trapped air in the hydraulic cylinder, oil is fed under pressure, which is controlled by the pressure gage (10d). The feed drive system described is a module independent from the original machine tool feed drive (milling feed drive system is shut off during entire machining process). The milling machine worktable, in this case, assumes the role of a stable platform to which a module is attached which assumes the function of the drive system. The feed drive system is shown in Fig. 15.

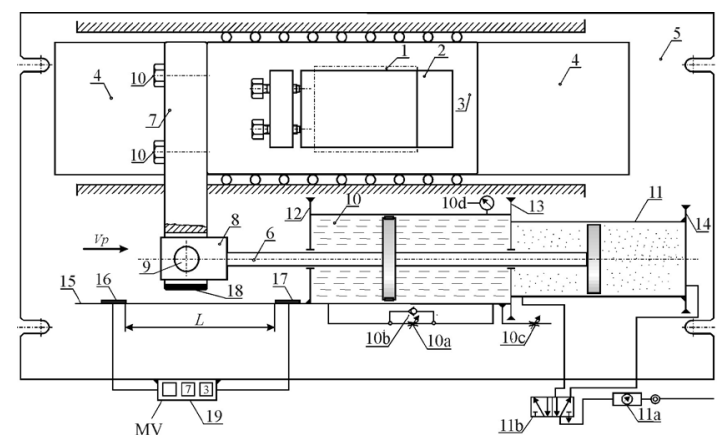

Fig. 14. Schema of the proposed feed drive system

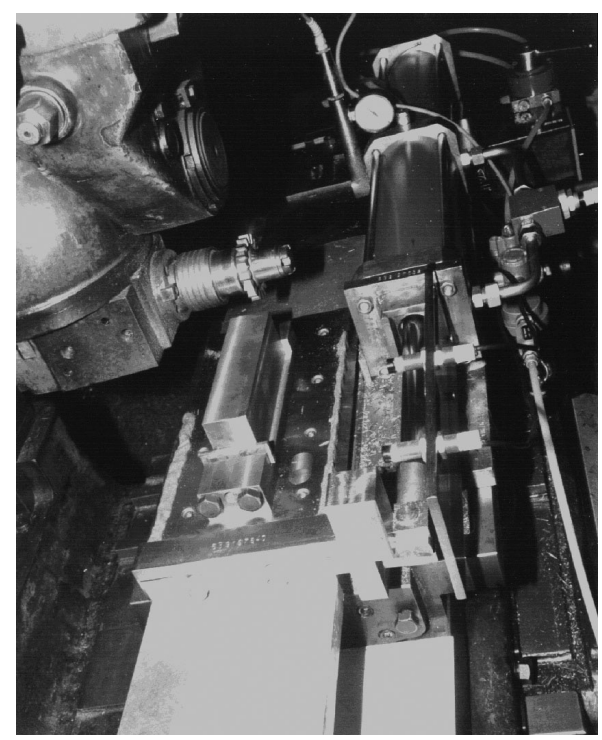

Fig. 15. Feed drive system mounted on the milling machine worktable

\section{TESTING OF FEED DRIVE SYSTEM}

Prior to experimental investigation, the feed drive system was tested. In addition to testing the geometric accuracy of the moving components of the feed drive system, and checking the stiffness of joints, the relationship between feed speed and axial force was also determined. The axial force exerted by compressed air in the pneumatic cylinder simulates the horizontal component of the cutting force, while the table speed is calculated as the ratio between $L$ and time of cutting $t$ (Fig. $14)$. By varying the input air pressure one a range of values for axial force $\left(F_{a i}\right)$ and time $\left(t_{i}\right)$ for which the table travels along path $(L)$ is derived. The active force $\left(F_{a}\right)$ is calculated based on the pressure which reads on the manometer of the air service unit and the diameter of the pneumatic cylinder. The described method was used with various damping rates, producing the experimental data shown in Table 1.

Statistical analysis of experimental data by regression analysis with the basic function of following form:

$$
\left(F_{a k}-C\right)=R_{r} \times v^{2}
$$

results with the regression equations of high degree of correlation (Table 2). In Eq. (59) $\left(F_{a k}-C\right)$ represents effective force which performs the movement. Namely, the constant $C$ includes friction forces and other opposing forces which are always present, while the member $R_{r}$ $\times v^{2}$ defines quadratic dependency of feed speed on effective force. This relationship $\left(R_{r} \times v^{2}\right)$ was derived from a set of Bernoulli equations within the theoretical investigation. Regression equations and correlation coefficients confirm this relationship (Table 2). Given in Table 2 are feed speeds and axial forces, derived by regression equations, as well as the percent deviations between the measured and calculated values. The differences in constant $C$ could be attributed to the influence of feed speed on the magnitude of friction force. The decrease of friction force is due to higher feed speeds, which is confirmed by statistical analysis.

\section{PRELIMINARY EXPERIMENTS}

In order to test the theoretical model proposed, as well as the physical prototype of 
Table 1. The results of measurement for pressure $p$, time $t$, the calculated force $F_{a}$ and feed speed $v p$

\begin{tabular}{|c|c|c|c|c|c|c|c|}
\hline \multicolumn{4}{|c|}{ Damping rate $R_{r 1}$} & \multicolumn{4}{c|}{ Damping rate $R_{r 2}$} \\
\hline $\begin{array}{c}p \\
{[\mathrm{bar}]}\end{array}$ & $\begin{array}{c}F_{a k} \\
{[\mathrm{~N}]}\end{array}$ & $\begin{array}{c}t \\
{[\mathrm{~s}]}\end{array}$ & $\begin{array}{c}v_{p} \\
{[\mathrm{~mm} / \mathrm{min}]}\end{array}$ & $\begin{array}{c}p \\
{[\mathrm{bar}]}\end{array}$ & $\begin{array}{c}F_{a k} \\
{[\mathrm{~N}]}\end{array}$ & $\begin{array}{c}t \\
{[\mathrm{~s}]}\end{array}$ & $\begin{array}{c}v_{p} \\
{[\mathrm{~mm} / \mathrm{min}]}\end{array}$ \\
\hline 1.5 & 1062 & 140 & 64.3 & 1 & 715 & 50 & 180 \\
\hline 2 & 1430 & 86 & 104.7 & 1.5 & 1052 & 32 & 281.3 \\
\hline 2.5 & 1788 & 65 & 138.5 & 2 & 1430 & 24 & 375 \\
\hline 3 & 2145 & 52 & 173 & 2.5 & 1788 & 19 & 473.8 \\
\hline 3.5 & 2502 & 44 & 204.6 & 2.9 & 2073 & 17 & 529.5 \\
\hline 4 & 2860 & 39 & 230.7 & 3.5 & 2502 & 15 & 600 \\
\hline 4.4 & 3146 & 35 & 257.3 & 4 & 2860 & 13 & 692.5 \\
\hline- & - & - & - & 4.4 & 3146 & 12 & 750 \\
\hline
\end{tabular}

Table 2. Results of statistical analysis

\begin{tabular}{|c|c|c|c|c|c|}
\hline \multicolumn{3}{|c|}{ Damping rate $R_{r 1}$} & \multicolumn{3}{|c|}{ Damping rate $R_{r 2}$} \\
\hline $\begin{array}{c}v_{p} \\
{[\mathrm{~mm} / \mathrm{min}]}\end{array}$ & $\begin{array}{l}F_{a k 1} \\
{[\mathrm{~N}]}\end{array}$ & $\begin{array}{l}D F \\
{[\%]}\end{array}$ & $\begin{array}{c}v_{p} \\
{[\mathrm{~mm} / \mathrm{min}]}\end{array}$ & $\begin{array}{l}F_{a k 2} \\
{[\mathrm{~N}]}\end{array}$ & $\begin{array}{l}D F \\
{[\%]}\end{array}$ \\
\hline 64.3 & 1204 & 14.2 & 180 & 872 & -15.7 \\
\hline 104.7 & 1430 & 8.5 & 281.3 & 1083 & -2.1 \\
\hline 138.5 & 1702 & 8.6 & 375 & 1361 & 6.8 \\
\hline 173 & 2058 & 8.7 & 473.8 & 1741 & 4.6 \\
\hline 204.6 & 2452 & 4.9 & 529.5 & 1994 & 7.8 \\
\hline 230.7 & 2828 & 3.1 & 600 & 2355 & 14.7 \\
\hline 257.3 & 3258 & -11 & 692.5 & 2896 & -3.6 \\
\hline- & - & - & 750 & 3272 & -12.8 \\
\hline \multicolumn{3}{|c|}{$\begin{array}{c}\text { Regression equation } F_{a k}-106.7=3.31 \times 10^{-3} \times v_{p}^{2} \\
r=0.993, s=10.1\end{array}$} & \multicolumn{3}{|c|}{$\begin{array}{c}\text { Regression equation } F_{a k}-72.5=4.53 \times 10^{-4} \times v_{p}^{2} \\
r r=0.992, s=11.3\end{array}$} \\
\hline
\end{tabular}

the feed drive, preliminary experiments were conducted. Extensive follow-up experimental investigation is planned in the future to determine the quality of a number of machining parameters derived by the novel method, as well as to compare them with those obtained by conventional methods.

Preliminary experimental investigation was conducted under following conditions:

- The machining was performed using feed drive of a universal milling machine PGU-3.

- Workpiece material: C1530, hardness 190 to $205 \mathrm{HB}$, with $0.44 \% \mathrm{C} ; 0.18 \% \mathrm{Si} ; 0.27 \% \mathrm{Mn}$; $0.011 \% \mathrm{~S} ;<0.010 \% \mathrm{P}$,

- Cutter: standard end mill 80X10X27N,

- Cutting regime parameters were as follows: cutting speed $22.6 \mathrm{~m} / \mathrm{min}$, feed speed 112.8 $\mathrm{mm} / \mathrm{min}$, cutting depth $1 \mathrm{~mm}$, cutting width $10 \mathrm{~mm}$.

The following parameters were monitored during the experiment:
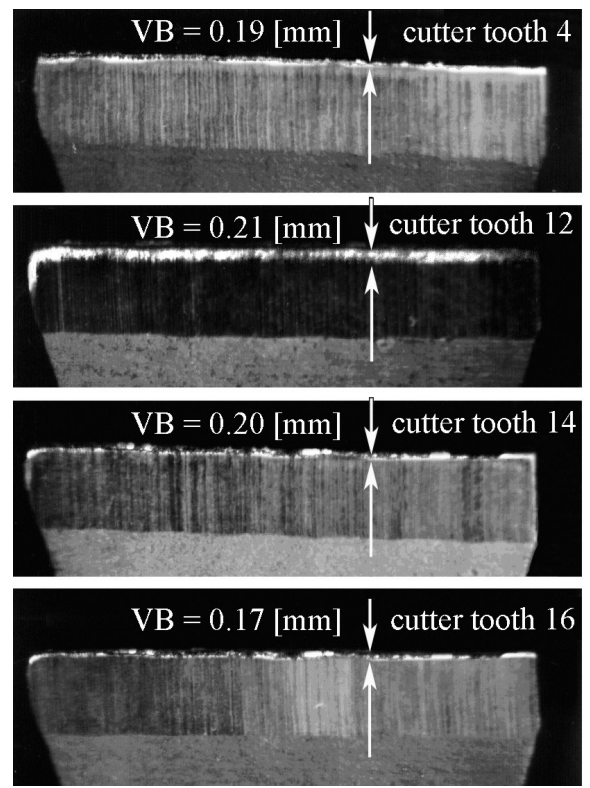

Fig. 16. Images of worn cutter teeth after 347.6 minutes of cutting 


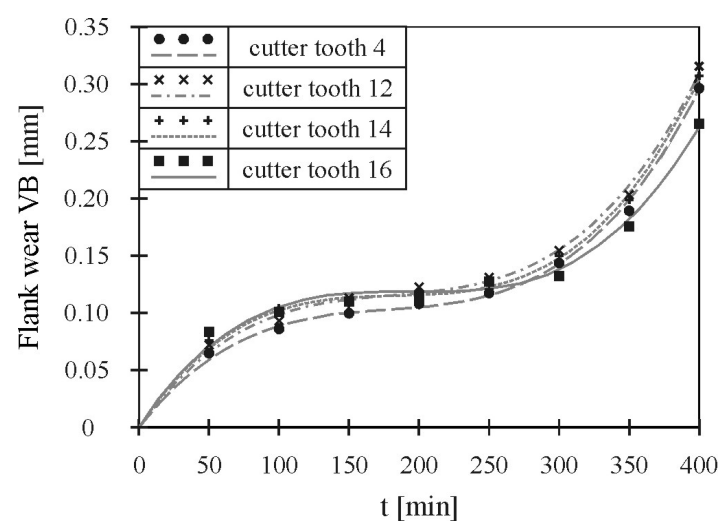

Fig. 17. Wear curve for characteristic cutter teeth in dependence of cutting time

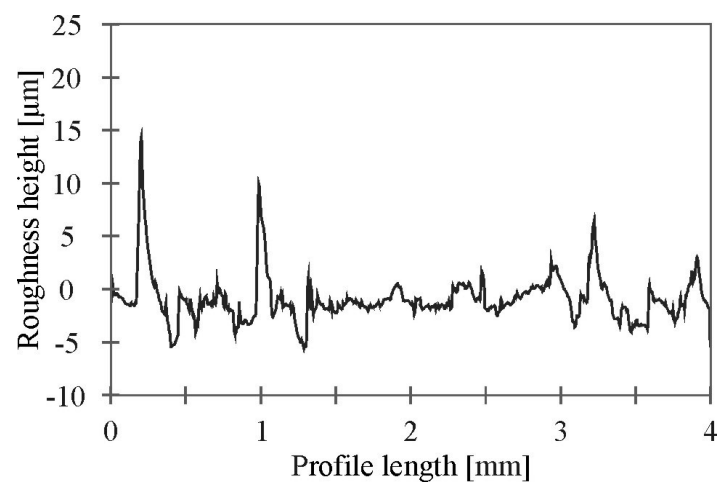

Fig. 18. Profile of machined surface after 31.8 minutes of cutting

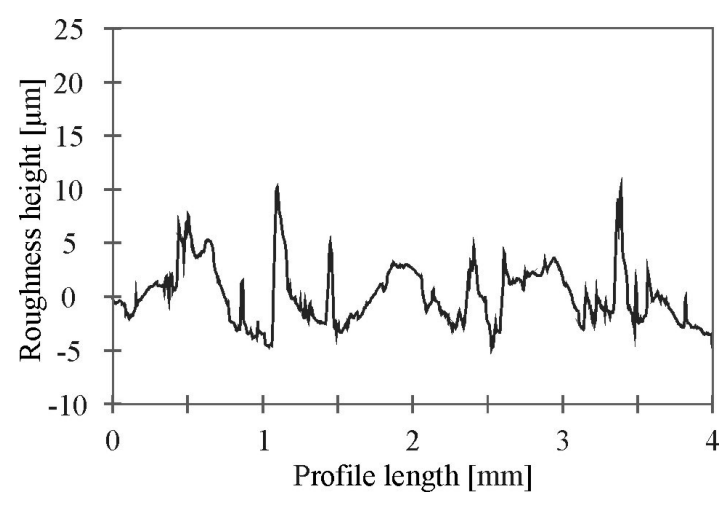

Fig. 19. Profile of machined surface after 347.6 minutes of cutting

- Mean flank wear on the four characteristic cutter teeth. As an example, in Fig. 16 images of worn teeth generated on Meiji Techno MC50 microscope are shown. Based on the measured flank wear, a diagram of wear curves is given in Fig. 17 for the characteristic cutter teeth,

- The profiles of the machined surface were taken after two cutting intervals, using Taylor Hobson - Talysurf 6 apparatus. The profiles are shown in Figs. 18 and 19.

\section{CONCLUSION}

The proposed theoretical model implicates the practical possibility of controlling feed motion in down milling by hydraulic damping, where the horizontal component of the cutting force is used to actuate motion. The theoretical model proposed should be taken as a fundamental model, which clearly implies the possibility of practical machining as described in this paper. Based on the proposed model, which can be conditionally treated as a static model, a dynamic testing of the feed drive system was also performed. The results of dynamic modelling show that the horizontal component of the cutting force can be successfully used as the active force in down milling feed motion. The results of dynamic modelling also show that the hydraulic damping allows a very precise control of the down milling feed motion. Testing of the physical prototype of the feed drive system also allowed preliminary experimental investigation to be performed on a real machining system.

The results of preliminary experimental investigation allow the following conclusions:

- Down milling is possible according to the proposed method, which completely verifies the proposed theoretical model.

- Tool life and surface quality obtained by the proposed method are of the same order of magnitude as those obtained by conventional machining methods.

Based on the investigation results it is the authors' opinion that the feed drive systems of this type can have broad practical applications. Their advantage in comparison with conventional feed drive systems is their ability to shift feed speed continuously as well as the lower system cost. The results achieved so far provide a solid ground for continuation of both theoretical and experimental investigations. 


\section{REFERENCES}

[1] Stephenson, D.A., Agapiou, J.S. (2006). Metal Cutting Theory and Practice, $2^{\text {nd }}$ ed. CRC Press, Boca Raton.

[2] Boothroyd, G., Knight, W.A. (2006). Fundamentals of machining and machine tools, $3^{\text {rd }}$ ed. CRC Press, Boca Raton.

[3] Sai, K., Bouzid, W. (2005). Roughness modeling in up-face milling. The International Journal of Advanced Manufacturing Technology, vol. 26, no. 4, p. 324-329.

[4] Davim, J.P., Clemente, V.C., Silva, S. (2009). Surface roughness aspects in milling MDF (medium density fibreboard). The International Journal of Advanced Manufacturing Technology, vol. 40, no. 1-2, p. 49-55.

[5] Mansour, A., Abdalla, H. (2002). Surface roughness model for end milling: a semifree cutting carbon casehardening steel (EN 32) in dry condition. Journal of Materials Processing Technology, vol. 124, no. 1-2, p. 183-191.

[6] Miao, J.C., Chen, G.L., Lai, X.M., Li, H.T., Li, C.F. (2007). Review of dynamic issues in micro-end-milling. The International Journal of Advanced Manufacturing Technology, vol. 31, no. 9-10, p. 897-904.

[7] Liu, X., Cheng, K. (2005). Modelling the machining dynamics of peripheral milling. International Journal of Machine Tools \& Manufacture, vol. 45, no. 11, p. 1301-1320.

[8] Altintas, Y., Montgomery, D., Budak, E. (1992). Dynamic peripheral milling of flexible structure. Journal of Engineering for Industry, vol. 114, no. 2, p. 137-145.

[9] Zeng, W., Jiang, X., Blunt, L. (2009). Surface characterisation-based tool wear monitoring in peripheral milling. The International Journal of Advanced Manufacturing Technology, vol. 40, no. 3-4, p. 226-233.

[10] Xu, C., Chen, H., Liu, Z., Cheng, Z. (2009). Condition monitoring of milling tool wear based on fractal dimension of vibration signals. Strojniški vestnik - Journal of Mechanical Engineering, vol. 55, no. 1, p. 15-25.

[11] Mann, B.P., Insperger, T., Bayly, P.V., Stepan, G. (2003). Stability of up-milling and down- milling, part 2: experimental verification. International Journal of Machine Tools \& Manufacture, vol. 43, no. 1, p. 35-40.

[12]Zhao, M.X., Balachandran, B. (2001). Dynamics and stability of milling process. International Journal of Solids and Structures, vol. 38, no. 10-13, p. 2233-2248.

[13] Altintas, Y., Budak, E. (1995). Analytical prediction of stability lobes in milling. CIRP Annals - Manufacturing Technology, vol. 44, no. 1, p. 357-362.

[14] Wan, M., Zhang, W.H. (2006). Calculations of chip thickness and cutting forces in flexible end milling. The International Journal of Advanced Manufacturing Technology, vol. 29, no. 7-8, p. 637-647.

[15] Kumar Reddy, N.S., Rao, P.V. (2005). Selection of optimum tool geometry and cutting conditions using a surface roughness prediction model for end milling. The International Journal of Advanced Manufacturing Technology, vol. 26, no. 1112, p. 1202-1210.

[16] Chu, C.H, Chen, J.T. (2006). Tool path planning for five-axis flank milling with developable surface approximation. The International Journal of Advanced Manufacturing Technology, vol. 29, no. 7-8, p. 707-713.

[17] Park, S.C., Choi, B.K. (2000). Tool-path planning for direction-parallel area milling. Computer-Aided Design, vol. 32, no. 1, p. 1725.

[18] Balič, J., Korošec, M. (2002). Intelligent tool path generation for milling of free surfaces using neural networks. International Journal of Machine Tools \& Manufacture, vol. 42, no. 10, p. 1171-1179.

[19] Sonmez, A.I., Baykasoglu, A., Dereli, T., Filiz, I.H. (1999). Dynamic optimization of multi-pass milling operations via geometric programming. International Journal of Machine Tools \& Manufacture, vol. 39, no. 2, p. 297-320.

[20] Čuš, F., Župerl, U., Kiker, E. (2007). A modelbased system for the dynamic adjustment of cutting parameters during a milling process. Strojniški vestnik - Journal of Mechanical Engineering, vol. 53, no. 9, p. 524-540. 
[21]Dereli, T., Filiz, I.H., Baykasoglu, A. (2001). Optimizing cutting parameters in process planning of prismatic parts by using genetic algorithms. International Journal of Production Research, vol. 39, no. 15, p. 3303-3328.

[22] Palanisamy, P., Rajendran, I., Shanmugasundaram, S. (2007). Optimization of machining parameters using genetic algorithm and experimental validation for end-milling operations. The International Journal of Advanced Manufacturing Technology, vol. 32, no. 7-8, p. 644-655.

[23] Čuš, F., Milfelner, M., Balič, J. (2006). An intelligent system for monitoring and optimization of ball-end milling process. Journal of Materials Processing Technology, vol. 175, no. 1-3, p. 90-97.

[24]Župerl, U., Čuš, F., Muršec, B., Ploj, T. (2006). A generalized neural network model of ball-end milling force system. Journal of Materials Processing Technology, vol. 175, no. 1-3, p. 98-108.
[25] Palanisamy, P., Rajendran, I., Shanmugasundaram, S. (2008). Prediction of tool wear using regression and ANN models in end-milling operation. The International Journal of Advanced Manufacturing Technology, vol. 37, no. 1-2, p. 29-41.

[26] Tansel, I.N., Ozcelik, B., Bao, W.Y., Chen, P., Rincon, D., Yang, S.Y., Yenilmez, A. (2006). Selection of optimal cutting conditions by using GONNS. International Journal of Machine Tools \& Manufacture, vol. 46, no. 1, p. 26-35.

[27] Ozcelik, B., Oktem, H., Kurtaran, H. (2005). Optimum surface roughness in end milling Inconel 718 by coupling neural network model and genetic algorithm. International Journal Advanced Manufacturing Technology, vol. 27, no. 3-4, p. 234-241.

[28]Župerl, U., Čuš, F., Gečevska, V. (2007). Optimization of the characteristic parameters in milling using the PSO evolution technique. Strojniški vestnik - Journal of Mechanical Engineering, vol. 53, no. 6, p. 354-368. 